\title{
Feedback in Online Translation Courses and the Covid Era
}

\author{
Miguel A. Jiménez-Crespo ${ }^{\text {[0000-0002-4938-3095] }}$ \\ ${ }^{1}$ Rutgers University NJ 08901 USA \\ ${ }^{2} 15$ th Seminary P1., 5th Floor, New Brunswick, NJ, 08901, USA \\ jimenez.miguel@rutgers.edu
}

\begin{abstract}
The Covid pandemic upended translation teaching globally. The forced move to online teaching represented a gargantuan challenge for anyone only experienced in face-to-face teaching. Online translation teaching requires distinct approaches to guarantee that students can reach the targeted learning goals. This paper presents a literature review on the provision of effective feedback in the light of these drastic changes in translation teaching as well as a description as how existing research on online feedback for translation training has been applied to the design of online courses at the translation program at Rutgers University.
\end{abstract}

Keywords: Translation training, feedback, online feedback

\section{Introduction}

The Covid pandemic upended translation teaching globally and the forced move to online teaching represented a gargantuan challenge for anyone only experienced in face-to-face teaching [8]. Online translation teaching requires distinct approaches to guarantee that students can reach the targeted learning goals $[4,10]$. This paper presents a literature review on the provision of effective feedback in the light of these drastic changes in translation teaching. This is, without any doubt, one of the most important issues in online courses to successfully engage learners and to improve their translation skills. This is supported by research both in face-to-face and online courses, because "without feedback, adult learners will experience anxiety, frustration, and often failure, and so will their teachers" [7: 15]. Feedback can become an extremely time-consuming activity, and more so for those who had to quickly adapt to online environments. Providing feedback in an efficient manner maximizes the intended effect concerns anyone engaged in online education. This article provides a brief overview of existing research on the topic of online translation teaching and the role of feedback with the goal of providing applied recommendations. In addition to the literature review, it presents examples of how the certificate and Masters program at Rutgers University has implemented these feedback practices into their courses. 


\section{First things first: feedback provision based on translation competence models}

Feedback can only be built upon a solid framework that includes effective online teaching methodologies and previously established models of what is precisely being taught. Two basic notions here are "translation competence" and "socioconstructivist" teaching methodologies. "Translation competence" refers to the skillset required to translate at a professional level not possessed by all bilinguals [14, 15]. Existing models of "translation competence", such as those by the research group PACTE of the European Masters Association (EMT), represent a research-based framework to establish specific learning goals for each course or program. These competence frameworks are componential models, meaning that they consist of a number of subcompetences. In the case of the PACTE model [15], these subcompetence are: (1) linguistic (language, specialized language, drafting genres such as contracts or brochures), (2) extralinguistic (knowledge about specialized domains or areas of knowledge), (3) knowledge about translation (processes, ethics, strategies), (4) instrumental (TM tools, MT, online documentary sources, data mining strategies) as well as the main one, (5) the strategic subcompetence (the ability to mobilize all the other components to solve quickly any specific translation problem) [14]. These main competences in the models contain non-finite lists of sub skills for each component that research has shown professional translators possess, and consequently, assume to be those that translation students need to acquire. These models not only provide an overall framework to structure what type of translations are presented, but also to plan specific task-based activities, pre -or post- translation, that can help build translation competence $[1,5]$. This is a topic that cannot be fully expanded here due to space constraints, but in Jiménez-Crespo [3] readers can get more information on how to build translation programs and courses up using these models of translation competence. They are a key foundation to provide a framework with specific learning goals, to scaffold learning activities, plan projects, testing and evaluations, etc. They are also key to direct any type of feedback towards the achievement and evaluation of those goals.

The second basic area of interest is online teaching methodology. Translation is generally not well-suited for what is known as "transmissionist" approaches [5]. These are the "classic" approaches in which the instructor lectures from a stand or a videoconference, students translate a model and then, in turn, receive the authoritative corrections from the instructor. Students are then assumed to "somehow" integrate this learning into their active competencies. Research has shown that translation is a "performance-based" skill and therefore, teaching cannot primarily be done by lecturing about "how" to do it, meaning teaching from the podium (or videoconference/ pre-recorded instructional videos) general principles or agreeing / disagreeing with students that their proposed translations are right or wrong. This is not fully conductive for students to actively integrate the learning contents in their future translation performance. Lecturing is definitely necessary for some parts of the learning process, but translation is about $20 \%$ "declarative knowledge", that is, knowledge "about" the process, and 80\% "operational knowledge", that is, "how to do something" [14]. 
Currently, research in the didactics of translation shows that the most popular methodologies, especially for online contexts, are the "socioconstructivist" approaches [6], as well as "situated-learning" ones [2]. These perspectives indicate that translation learning is fundamentally an interactive, collaborative, "socio-personal process". Learners are at the center of their learning process and they socially construct their knowledge. This means that participants discover knowledge by themselves through collaboration in real-life professional translation assignments or specific tasks in the overall cycle of translation production. In this regards, online learning is an ideal context to replicate real-life professional translation assignments. Instructors are seen as facilitators or guides rather than authoritative figures that have the final say in translation solutions, and they are in charge of creating real-life simulations such as the projects by Olvera-Lobo et al $[12,13]$. In some of these online courses, translation assignments resemble freelance team jobs in which students can rotate in their roles as managers, terminologists, translators, and revisers, while trainers play the role of the client, as well as the guide that provides informative, effective feedback to point students towards possible strategies, resources and mechanisms to identify solutions to translation problems.

Last but not least, the ultimate goal of translation education is to produce "experts" in a specific skill, and according to cognitive science, feedback plays a fundamental role. To achieve expertise in any field, structured "deliberate practice" that results from "regular engagement in specific activities directed at performance enhancement in a particular domain", with "appropriate difficulty and informative feedback" [16: 29], is in fact the most efficient way. Any practice, in this context, requires a constant dedication and processing translations at the "growing edge". This means that activities have to be of increasing difficulty, but it requires participants to make an effort to complete them. The here then is how to organize challenging and engag ing translation courses in which students receive this "informative feedback" that will make them grow.

\section{Types of translation feedback online}

Feedback in online courses will first and foremost depend on the nature or type of online instruction. Generally, online training can be synchronous or asynchronous, or a combination of both. Synchronous training involves training through videoconferencing systems in which all students meet at the same time, while asynchronous courses are organized as self-paced courses in which students do not meet at a specific time with other classmates or the trainer, but they do have specific deadlines to complete projects, assignments or quizzes, participate in forums or videoforums, watch prerecorded lectures, etc. In addition, translation training can be "process-oriented" and "product-oriented". In "process-oriented" training, instructors focus on translation strategies rather than the target text: basic concepts and models prior to translation. In "product-oriented" approaches, classes are focused on analysis of errors or in- 
adequacies related to style and content in progression of representative texts proposed. Feedback will thus depend on the combination of teaching approaches from the options above. Most importantly, it needs to be taken into account that feedback in online courses can be extremely time-consuming for the instructor. Therefore, providing effective, meaningful feedback that has the maximum impact on students learning is paramount for any effective instruction, both for the students to achieve their goals, as well as for the instructor to efficiently distribute his/her limited time resources.

Studies on the provision of online feedback emerged from the early days of the WWW [11]. For those interested in this topic, research on the role of feedback in regular face to face settings can also help provide a sounder foundation [9]. As a broad summary, it has been found that the overall translation process and the quality of the outcome partially correlate to (1) the type of feedback employed, (2) how it is administered, and (3) how it is presented. In addition, it should be added that online feedback does not only come from the instructor, but (4) it can also be provided by peers (e.g. group work online or collaboration in documents in cloud-based servers, exchanging translations or exchanging access as reviewers in cloud-based CAT tools), professionals (internships) or the crowd (e.g. asking questions in Proz.com or participating in crowdsourcing initiatives), as well as the provision of automated feedback (in terms of automated quizzes, multiple choice selection, etc.). Neunzig and Tanqueiro [11] published the first and most comprehensive classification of the types of feedback in online translation courses. They conducted a study to identify how different types of feedback correlate to acquisition of learning objectives and improvements in the quality of students' translations. Online learning technologies have evolved since the publication of this study (for example, videoconferencing now allows to conduct lectures, break up students into virtual discussion rooms, collaboration in cloud-based translation documents in real life during lectures in Google Docs or Word 365). Nevertheless, the main categories of feedback are still relevant for anyone interested in the provision of efficient feedback. These categories are first and foremost categorized depending on (1) how the feedback is administered, and (2) when it is administered:

1. How the feedback is administered: Individual or non-individual feedback - provided to the entire group.

\section{When it is administered:}

2.1. Delayed Individual feedback. Delayed individual feedback is the most common form of feedback in online courses, and entails providing a corrected translation with comments. This is done for exams or individual graded assignments. This type of feedback tends to be highly beneficial for grammar or language mistakes, but a bit less so for other types of translation errors. In order to improve the efficiency of this type of feedback, strategies such as having an online final translation portfolio in which students submit a final "polished" translation of "publishable" quality for each graded assignment, guarantees that the time invested in providing feedback by instructors is meaningfully and actively integrated by the student. 
2.2. Individual feedback - Contiguous. This type of feedback refers to interventions while the students are conducting the translation through prompts or pop-up messages. It can be informative, just indicating whether the answer provided is true or false, or indicating the type of error that happened. Contiguous feedback can also be corrective, and it is divided into simple corrective feedback and elaborate feedback. Elaborate feedback takes the form of guidelines or prompts that help students find the right answer, or indications of the most appropriate strategy to find an acceptable solution. It could also entail presenting a possible solution with an explanation. Building this type of feedback into the learning process can be complex and time consuming. One possible way to integrate this type of feedback into a synchronous class involves having a class connected to a videoconferencing system and at the same time have all students be part of a cloud-based shared doc (in Google Docs or Microsoft 365 for example). A student can type a proposed solution and the instructor, and students, can comment real time on the proposal by student, correcting any possible proposed rendering.

2.3. Non-individual feedback-Anticipatory. This involves providing instructions and guidelines, key problem-solving strategies and-or attention to key translation problems and issues prior to engagement in the translation. Normally translations need to include the "translation brief", a notion brought to us by functionalist theories of translation (Nord 1997) where instructions for the translation are provided. This includes the intended audience (e.g. Latin America, US or Spain for Spanish), intended purpose, function of the translation (e.g. a company wants to get a product sold in this market, a local government wants to advertise its historical and cultural features to boost tourism in an online website), etc. Anticipatory feedback can be provided in terms of an extended video that presents the translation and identifies the main challenges or "difficulties", what the PACTE group refers to as "rich points" [15] that connect the actual translation assignment to the learning goals for the translations. These video presentations do not include actual solutions to any problem, but rather, point at the problem, frame it, and direct students to possible mechanisms to solve it. This is similar to the most effective feedback found by Neunzig and Tanqueiro [11], "elaborate feedback" that provides guidelines and possible ways to solve problems, rather than the solution itself. For example, if a text includes any measurements, students can be reminded that $\mathrm{km}$ or hectares need to be adjusted for a US audience that is not acquainted with them. Rather than indicating the solution, anticipatory feedback points at the resources to solve the problem, such as Google conversion tools. Similarly, a specialized text about international trade can contain specialized terminology that can be found in terminology databases such as the IATE European Union Database $^{1}$. Nevertheless, it is key for students in this terminological search to learn that they need to include the specialized domain of the source text in question in the search so that they obtain accurate results. Another example can be dialectal variation. In the case of Spanish, students can be directed to find the most frequent term for international or neutral Spanish, or the term preferred for any country the translation is

\footnotetext{
${ }^{1}$ https://iate.europa.eu/
} 
intended to. For this purpose, dialectal variation tools such as Diatopix ${ }^{2}$ can be used (only for English, French, Spanish and Portuguese).

2.4. Non-individual - Delayed. This type of feedback to the entire group can come in form of a video explaining the main problems in a graded translation assignment summarizing the main issues, how to solve them, main strategies to avoid common pitfalls in the exam or assignment. It can also come in form of a translation sample from the course with the most common issues critically discussed, pointing especially at solutions to common translation problems, lack of problem identification by students (a common issue for novices), etc.

\section{Additional types of feedback}

3.1. Anticipatory or delayed - Consult with translation model. This was found to be the least effective of them all, and though it is extremely useful in some contexts (i.e. for translation analysis, criticism, etc.) it is not recommended as general method. It is possible to produce as a collaborative effort in the course, synchronously or asynchronously (in a shared doc or using a discussion forum), a translation model that is the result of a training session and thus, the result of intensive feedback and studentsstudents and students-instructor collaboration.

3.2. Simple delayed individual feedback. Students provide a translation and the professor grades and comments on the translation. This is one of the basic approaches and it is helpful to some extent, but in itself it is time-consuming and it is not fully efficient to increase the quality of students' performance (if compared to other more interactive methods based on socioconstructivist approaches that, nevertheless, do include commentary and editing by instructors).

\section{How feedback is incorporated at Rutgers University online translation courses}

The feedback loops implemented at asynchronous online translation courses at Rutgers University entail primarily a dynamic gradual process. In each unit, students receive initially anticipatory feedback in the form of video presentations on the unit translations (as well as any other theoretical presentations, readings, etc.) focusing on the "rich points" in each translation and possible problem-solving strategies (students need to implement them and find their own solution alone or in pairs-groups depending on the assignment). These "rich points" are connected to the learning goals for each unit and they are representative of the most common issues on the prototypical textual genres assigned (business letter, recipes, children's stories, purchase contracts, medical inserts, UN resolution, research paper, patents, etc.). Students, in groups or individually, submit a draft of the translation. An online forum then opens where the instructor directs students to provide commented solutions for these "rich points".

${ }^{2}$ http://olst.ling.umontreal.ca/diatopix/?lg=en 
Over several days, students and instructor engage in a discussion (on forums or videoforums) on the main issues, and the instructor proactively comments and presents and guides students towards the best solutions and problem-solving strategies. Students then have to incorporate the comments from the forums in their translation drafts and provide a "final translation". This translation is then graded and returned with comments and this can be considered as delayed individual feedback. Over the course of the online unit, students have already received group or non-individual anticipatory feedback, elaborate feedback in the forums, and peer feedback. In addition to the individual delayed feedback from the instructor, and the group delayed feedback in the form of a video that summarizes the main issues most students had in their final version of the translation, this methodology provides a richer approach in terms of online feedback and a better approach to help students incorporate in their own learning style and progression the teachings from each unit. Alternatively, in synchronous teaching, the use of videoconferencing combined with shared cloud documents can provide an ideal platform for instructor-entire class, instructor- class groups to collaborate on translation assignments, leading to the production of a group translation version that is the result of a collaborative learning process.

\section{Conclusions}

Translation feedback in didactic contexts can become an extremely time-consuming activity, and more so for those who had to quickly adapt to online environments due to the Covid pandemic. Providing feedback in an efficient manner that maximizes the intended effect on the learner should be the main goal of anyone engaged in online education. This paper has reviewed the significance of providing effective feedback in online environments to both improve the learning process of students, while taking into considerations the time limitations for instructors. It has presented an updated categorization of online feedback based on the publication by Neunzig and Tanqueiro [11] and how this has been applied in the online translation program at the undergraduate and graduate program at Rutgers University. To finish with, it should be mentioned that anonymous students course evaluations rate similarly online and face to face courses over the years, witness to the fact that the online feedback model developed helps students perceive that both environments are equally suited for their translation competence acquisition process.

\section{References}

1. González Davis, M.: Multiple voices in the translation classroom. Amsterdam-Philadelphia: John Benjamins (2004).

2. González-Davis, M., Enríquez-Raido, V: Situated learning in translation and interpreting training. New York-London, Roultledge (2018).

3. Jiménez-Crespo, M. A.: Building from the ground up: on the necessity of using translation competence models in planning and evaluating translation and interpreting programs. 
Cuadernos de ALDEEU, Special Issue, Translation and Interpreting Training, 11-42 (2013).

4. Jiménez-Crespo, M. A.: Translation training and the Internet: two decades later. TIS: Translation and Interpreting Studies 9, 33-56 (2015).

5. Kelly, D.: Handbook for Translation Trainers. Manchester, St. Jerome (2018).

6. Kiraly, D.: A Social Constructivist Approach to Translator Education - Empowerment from Theory to Practice. Manchester: St Jerome (2000).

7. Knowles, M.: Self-directed learning: A guide for learners and teachers. Chicago, Follett Publishing Company (1975).

8. Luo, X.: Translation in the time of COVID-19. Asia Pacific Translation and Intercultural Studies (2021). DOI: 10.1080/23306343.2021.1903183

9. Massey, G., and Brändli, B.: Collaborative feedback flows and how we can learn from them: investigating a synergetic learning experience in translator education”. In: Kiraly, D. (ed.) Towards Authentic Experiential Learning in Translator Education, pp. 177-199. Göttingen: Mainz University Press (2021).

10. Massey, G.: Process-Oriented Translator Training and the Challenge for E-Learning. Meta: Translators' Journal 50 (2), 626-633 (2005).

11. Neunzig, W., Tanqueiro, H.: Teacher Feedback in Online Education for Trainee Translators. Meta: Translators' Journal 50 (4) (2005). https://www.erudit.org/en/journals/meta/ 1900-v1-n1-meta1024/019873ar.pdf

12. Olvera Lobo, María D. et al.: Translator Training and Modern Market Demands. Perspectives: Studies in Translatology 13(2), 132-142 (2005).

13. Olvera-Lobo, María D. et al.: Teleworking and Collaborative Work Environments in Translation Training.” Babel 55 (2), 165-180 (2009). http://www.ugr.es/ robinson/ 2009_babel_55.pdf

14. PACTE. "Investigating Translation Competence: Conceptual and Methodological Issues. Meta: Translators' Journal 50, 609-619 (2005). https://ddd.uab.cat/pub/artpub/ 2005/137444/meta_a2005v50n2p609.pdf

15. PACTE. Researching Translation and Interpreting Competence by PACTE Group. [Benjamins Translation Library, 127]. Amsterdam-Philadelphia: John Benjamins (2017).

16. Shreve, G. M.: Translation and expertise: the deliberate practice. Journal of Translation Studies 9: 27-42 (2006). 